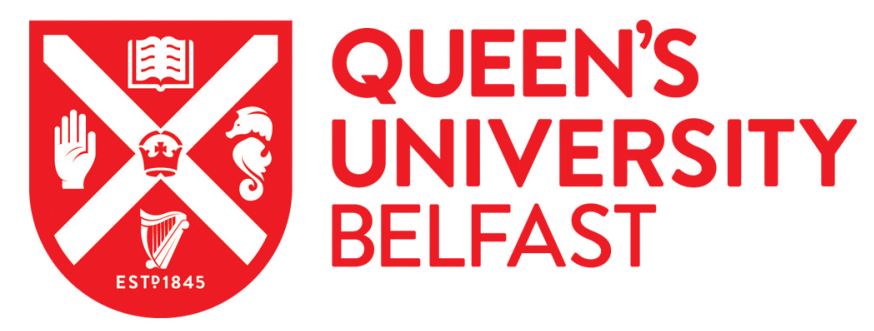

\title{
Chylomicron remnants potentiate phenylephrine-induced contractions of rat aorta by an endothelium-dependent mechanism.
}

Grieve, D., Avella, M. A., Botham, K. M., \& Elliott, J. (2000). Chylomicron remnants potentiate phenylephrineinduced contractions of rat aorta by an endothelium-dependent mechanism. Atherosclerosis, 151(2)(2), 471-480. https://doi.org/10.1016/S0021-9150(99)00432-3

Published in:

Atherosclerosis

Document Version:

Publisher's PDF, also known as Version of record

Queen's University Belfast - Research Portal:

Link to publication record in Queen's University Belfast Research Portal

\section{General rights}

Copyright for the publications made accessible via the Queen's University Belfast Research Portal is retained by the author(s) and / or other copyright owners and it is a condition of accessing these publications that users recognise and abide by the legal requirements associated with these rights.

Take down policy

The Research Portal is Queen's institutional repository that provides access to Queen's research output. Every effort has been made to ensure that content in the Research Portal does not infringe any person's rights, or applicable UK laws. If you discover content in the Research Portal that you believe breaches copyright or violates any law, please contact openaccess@qub.ac.uk. 


\title{
Chylomicron remnants potentiate phenylephrine-induced contractions of rat aorta by an endothelium-dependent mechanism
}

\author{
David J. Grieve ${ }^{1}$, Michael A. Avella, Kathleen M. Botham, Jonathan Elliott* \\ Department of Veterinary Basic Sciences, Royal Veterinary College, Royal College Street, London NW 1 OTU, UK
}

Received 24 May 1999; received in revised form 20 September 1999; accepted 8 October 1999

\begin{abstract}
The effects of chylomicron remnants on endothelium-dependent contraction of rat aorta were studied in vitro. Chylomicron remnant particles were prepared in vivo from male Wistar rats and were incubated with aortic rings for 45 min before concentration contraction response curves were constructed to phenylephrine. Both native and oxidised chylomicron remnants significantly increased vessel sensitivity to this agonist. Oxidised chylomicron remnants also significantly increased the maximum response. This potentiation was abolished by endothelial removal, but was still evident in the presence of $N^{\omega}$-nitro-L-arginine, with or without cyclo (D- $\alpha$-aspartyl-L-prolyl-D-valyl-L-leucyl-D-tryptophyl) (BQ-123), indomethacin or superoxide dismutase. The study demonstrates, for the first time, that lipoprotein particles of dietary origin potentiate vascular contractions. This effect is endothelium-dependent, but is not due to inhibition of basal nitric oxide production or to stimulation of endothelin, superoxide or a cyclo-oxygenase-derived product. (c) 2000 Elsevier Science Ireland Ltd. All rights reserved.
\end{abstract}

Keywords: Chylomicron remnants; Rat aorta; Endothelium-derived constricting factor; Nitric oxide

\section{Introduction}

In addition to the fact that vessels from atherosclerotic and hypercholesterolaemic animals demonstrate impaired agonist-induced endothelium-dependent relaxation, it has been reported that these vessels also show potentiation of vascular contraction which is dependent on the presence of their endothelium [1]. These effects are thought to be attributable to accumulation of cholesterol from lipoproteins, namely low-density lipoprotein (LDL), within the artery wall. Previous studies

Abbreviations: EDCF, endothelium-derived constricting factor; EDHF, endothelium-derived hyperpolarising factor; 5-HT, 5-hydroxytryptamine; IDM, indomethacin; KHS, Krebs-Henseleit solution; LDL, low density lipoprotein; L-NOARG, $N^{\omega}$-nitro-L-arginine; MDA, malondialdehyde; NO, nitric oxide; PE, phenylephrine; SOD, superoxide dismutase; TBARS, thiobarbituric acid reactive substances.

* Corresponding author. Tel.: +44-171-4685266; fax: +44-1713881027.

E-mail address: jelliott@rvc.ac.uk (J. Elliott)

${ }^{1}$ Present address: Department of Cardiovascular Medicine, Guy's, King's and St. Thomas' School of Medicine, Bessemer Road, London SE5 9PJ, UK. have failed to show a significant effect of native LDL on endothelium-dependent contraction [2,3]. However, when the particles are oxidised, the modified LDL has been found to cause potentiation of responses to vasoconstrictor agents in an endothelium-dependent manner in rabbit femoral artery, porcine coronary artery and rat aorta [2-4], supporting the putative role of oxidative modification in the atherosclerotic process [5].

Evidence from previous studies on endothelium-dependent contraction performed using vessels from atherosclerotic and hypercholesterolaemic animals and oxidised LDL has suggested that the observed potentiation of these responses is due to inhibition of the basal release of nitric oxide (NO). In rabbit aorta, hypercholesterolaemia has been shown to potentiate contractions to acetylcholine which are normalised by dietary L-arginine supplementation [6], and increased 5-hydroxytryptamine (5-HT) and noradrenaline-induced contractions observed in atherosclerotic rabbit aorta have been found to be normalised by addition of $N^{\omega}$-nitro-Larginine (L-NOARG) [7]. Furthermore, oxidised LDLinduced potentiation of contractions to 5-HT in porcine coronary artery, and phenylephrine (PE) in rat aorta is abolished in the presence of $\mathrm{L}-N^{\mathrm{G}}$-nitroarginine $[4,8]$. 
These findings support the idea that inhibition of release of NO is the mechanism causing the endotheliumdependent potentiation of the action of vasoconstrictor agents observed in vessels from atherosclerotic and hypercholesterolaemic animals. However, in many of these vessels, distinguishing between receptor-mediated NO release and basal release of NO by the vascular endothelium is difficult as many vasoconstrictor agonists also activate receptors on the endothelium to stimulate NO production $[9,10]$.

All previous investigations into the effect of lipoproteins on endothelium-dependent contraction have focused on LDL, despite the increasing implication of dietary lipoproteins in the atherogenic process. Chylomicron remnants have been shown to accumulate in both the rabbit and rat aorta in vivo [11-14], and apolipoprotein E-containing lipoproteins have been found in human aortic intima [15]. In addition, it has been shown that chylomicron remnants are metabolised by components of the artery wall, such as macrophages, fibroblasts and smooth muscle cells [16-18], and significant correlations have been found between elevated plasma chylomicron remnant concentrations and incidence of coronary artery disease [19,20]. Furthermore, recent work in our laboratory has found chylomicron remnants to inhibit endothelium-dependent relaxation in rat aorta, via an inhibitory action on the L-arginineNO pathway [21,22], findings supported by similar studies in rabbit aorta [23].

Tonic basal NO production can be assessed in the rat aorta by studying the contractions of this vessel to the selective $\alpha_{1}$-adrenoceptor agonist, PE in the presence and absence of an inhibitor of NO synthase [24,25]. No receptors for $\mathrm{PE}$ that are linked to $\mathrm{NO}$ release have been detected on the rat aortic endothelium. The aim of the present study was to investigate the effects of chylomicron remnants on basal NO production in the rat aorta.

\section{Materials and methods}

Male Wistar rats (300-350 g) were used throughout this study. They were housed under constant climatic conditions (temperature $21-22^{\circ} \mathrm{C}$, relative air humidity $50 \pm 5 \%$, constant 12 -h day length) with free access to food and water.

\subsection{Preparation of chylomicrons and chylomicron remnants}

Chylomicrons and chylomicron remnants were prepared in vivo as described previously [21]. Rats were tube-fed with 1.5 -ml corn oil, supplemented with $\alpha$-tocopherol $\left(4 \mathrm{mg} \mathrm{ml}^{-1}\right)$ as an antioxidant. After $\approx 1 \mathrm{~h}$, anaesthesia was induced (sodium pentobarbitone, 60 $\mathrm{mg} \mathrm{kg}{ }^{-1}$ body weight i.p.) and analgesic administered (carprofen, $5 \mathrm{mg} \mathrm{kg}^{-1}$ body weight s.c.), before the thoracic duct was cannulated with polyethylene tubing (external diameter $1.52 \mathrm{~mm}$ ) and the chyle collected overnight into a tube containing $2 \mathrm{mg}$ ampicillin as a preservative. Following collection, the chyle was layered under $\mathrm{NaCl}$ solution $\left(d 1.006 \mathrm{~g} \mathrm{ml}^{-1}\right)$ and centrifuged in a fixed-angle rotor for $6 \times 10^{5} \mathrm{~g} \cdot \min$ at $12^{\circ} \mathrm{C}$. The top fraction containing large chylomicrons (particle diameter $>100 \mathrm{~nm}$ ) was harvested and ampicillin in $0.9 \%$ saline was added (final concentration, $100 \mu \mathrm{g} \mathrm{ml}^{-1}$ ). For the in vivo preparation of chylomicron remnants, rats were anaesthetised (sodium pentobarbitone, $60 \mathrm{mg} \mathrm{kg}^{-1}$ body weight i.p.) and a functional hepatectomy was carried out by ligation of the anterior mesenteric artery, coeliac artery and hepatic portal vein. Chylomicrons containing $40 \mu \mathrm{mol}$ triacylglycerol and $50 \mathrm{mg}$ glucose were administered into the left ileolumbar vein and after 45 min blood was withdrawn from the bifurcation of the aorta and allowed to clot. The serum was obtained by centrifugation and the chylomicron remnants were isolated by ultracentrifugation for $6 \times 10^{7} \mathrm{~g} \cdot \min$ at $12^{\circ} \mathrm{C}$. The top $1-1.5 \mathrm{ml}$ was then layered under $\mathrm{NaCl}(d 1.006$ $\mathrm{g} \mathrm{ml}^{-1}$ ) and centrifuged for $3 \times 10^{7} \mathrm{~g}$ min at $12^{\circ} \mathrm{C}$. The top $1-1.5 \mathrm{ml}$ from this centrifugation containing the purified chylomicron remnants was harvested and $100 \mathrm{mg} \mathrm{ml}^{-1}$ ampicillin was added. The preparations were stored at $4{ }^{\circ} \mathrm{C}$ until required. Free and total cholesterol and triacylglycerol concentrations of the chylomicrons and chylomicron remnants were determined using commercially available enzyme-linked colorimetric assay kits (Boehringer Mannheim, Mannheim, Germany).

\subsection{Oxidative modification of chylomicron remnants}

Chylomicron remnant particles were oxidised by a modification of a previously used method [26]. The chylomicron remnants were dialysed against $10 \mathrm{mM}$ phosphate-buffered saline, $\mathrm{pH} 7.4$ for $5 \mathrm{~h}$ before incubation with a copper sulphate solution (final concentration, $10 \mu \mathrm{M}$ ) for $18 \mathrm{~h}$ at $37^{\circ} \mathrm{C}$. Lipoprotein oxidation was measured by the thiobarbituric acid reactive substances (TBARS) assay using a modification of a previously described method [27]. Tetraethoxypropane, which yields malondialdehyde (MDA) was used as a standard and results were expressed as nmol MDA $/ \mathrm{ml}$ lipoprotein. The oxidised chylomicron remnants were then dialysed against $0.9 \%$ saline for $5 \mathrm{~h}$ to remove the copper sulphate.

\subsection{Isolated vessel studies}

Rats were killed with a sodium pentobarbitone overdose (200 $\mathrm{mg} \mathrm{kg}^{-1}$ body weight i.p.) and the entire 
aorta rapidly removed, cleared of any surrounding connective tissue and thoracic portion cut into $3-\mathrm{mm}$ ring segments, taking care not to damage the endothelium. These rings were then placed in organ bath chambers containing $10 \mathrm{ml}$ modified Krebs-Henseleit solution at $37^{\circ} \mathrm{C}$ (KHS; composition (mM): $\mathrm{NaCl} 118$; $\mathrm{KCl}$ 4.57; $\mathrm{CaCl}_{2} 1.27 ; \mathrm{KH}_{2} \mathrm{PO}_{4} 1.19 ; \mathrm{MgSO}_{4} 1.19$; $\mathrm{NaHCO}_{3}$ 25; glucose 5.55) and prepared for isometric tension recording as previously described [21]. The vessel segments were held under $1 \mathrm{~g}$ resting tension (preliminary studies determined this to be the optimum resting tension) and allowed to equilibrate for 1 $\mathrm{h}$, before they were contracted by exchanging the KHS for a depolarising KHS, where the $\mathrm{NaCl}$ had been replaced isotonically with $\mathrm{KCl}(118 \mathrm{mM})$. After $15 \mathrm{~min}$, the depolarising KHS was replaced with KHS and resting tension re-established before several different experiments were performed. Firstly, in order to confirm that PE-induced contractions in rat aorta are modulated by endothelium-dependent basal NO production, concentration contraction response curves were constructed to PE $(1 \mathrm{nM}-10 \mu \mathrm{M})$ in endothelium-denuded (by gentle rubbing of the luminal surface with a wooden stick) rat aortic rings and in endothelium-intact vessel segments both in the presence and absence of $0.1 \mathrm{mM}$ L-NOARG. In addition, concentration contraction response curves to LNOARG $(0.1 \mu \mathrm{M}-1 \mathrm{mM})$ were also constructed in endothelium-intact and denuded vessel rings after precontraction with 30 and $10 \mathrm{nM} \mathrm{PE}$, respectively, in order to determine the concentration of L-NOARG that caused maximal potentiation of PE-induced contraction and to demonstrate endothelium-dependency of the observed response. Secondly, native or oxidised chylomicron remnants were added to the bathing solution to produce a concentration of $16 \mu \mathrm{M}$ cholesterol in the organ bath (preliminary studies demonstrated that this concentration produced the maximal effect) and incubated with the vessel segments for $45 \mathrm{~min}$. Control experiments, in which the same volume of 100 $\mu \mathrm{g} \mathrm{ml} \mathrm{m}^{-1}$ ampicillin was added instead of the lipoprotein, were carried out in parallel, using an adjacent vessel ring from the same animal. After this incubation period, cumulative concentration contraction response curves were constructed to PE $(1 \mathrm{nM}-10 \mu \mathrm{M})$. Thirdly, endothelium-denuded rat aortic rings and endothelium-intact vessel segments treated with $0.1 \mathrm{mM}$ L-NOARG were incubated with oxidised chylomicron remnants $(16 \mu \mathrm{M}$ cholesterol) for $45 \mathrm{~min}$. Again, control experiments, in which the same volume of $100 \mu \mathrm{g}$ $\mathrm{ml}^{-1}$ ampicillin was added instead of the lipoprotein, were carried out in parallel, and cumulative concentration contraction response curves were constructed to PE $(1 \mathrm{nM}-10 \mu \mathrm{M})$. Finally, vessel rings were incubated with oxidised chylomicron remnants $(16 \mu \mathrm{M}$ cholesterol) for $45 \mathrm{~min}$, in the presence of $0.1 \mathrm{mM}$
L-NOARG and either the endothelin antagonist, cyclo (D- $\alpha$-aspartyl-L-prolyl-D-valyl-L-leucyl-D-tryptophyl) (BQ-123) $(10 \mu \mathrm{M})$, indomethacin (IDM, $10 \mu \mathrm{M})$, superoxide dismutase (SOD, 150 units $\mathrm{ml}^{-1}$ ) or BQ1230, IDM and superoxide dismutase (SOD) together. Control experiments were carried out in parallel using adjacent vessel rings from the same animals incubated with oxidised chylomicron remnants, $0.1 \mathrm{mM} \mathrm{L-}$ NOARG and the same volume of vehicle in the absence of the antagonists. Cumulative concentration contraction response curves were then constructed to PE $(1 \mathrm{nM}-10 \mu \mathrm{M})$.

\subsection{Materials}

L-phenylephrine hydrochloride (PE), L-NOARG, BQ-123, indomethacin (IDM) and SOD were all purchased from Sigma Chemical (Poole, UK). All drugs, with the exception of IDM, were initially dissolved in deionised water (at $10 \mathrm{mM}$ ) and diluted in $0.9 \%$ saline. IDM was initially dissolved in ethanol (at 10 $\mathrm{mM}$ ) and diluted in $0.9 \%$ saline. All solutions were freshly prepared on the day of the experiment. Concentrations are expressed as the final concentration of each drug in the organ bath. Ethylenediaminetetraacetic acid (disodium salt), copper sulphate and trichloroacetic acid were purchased from BDH Laboratory Supplies (Poole, UK) and 4-6-dihydroxypyrimidine-2-thiol (2-thiobarbituric acid) and 1,1,3,3tetraethoxypropane from Sigma. Bovine serum albumin fraction $\mathrm{V}$ powder and ampicillin were purchased from Sigma, and corn oil and $\alpha$-tocopherol from domestic suppliers.

\subsection{Statistical analysis of data}

Data from organ bath experiments were expressed as increase in tone calculated as $g$ tension developed per mg tissue, and were plotted against log agonist concentration. Cumulative concentration contraction response curves for each vessel segment were fitted to the single site logistic equation:

Increase in tension $=E_{\max } A^{n} /\left(A^{n}+\mathrm{EC}_{50}^{n}\right)$

by a modified Marquart procedure using Multifit ${ }^{\circledR}$ (Day Computing, Cambridge, UK) running on a Macintosh 475. $E_{\max }$ represents the maximum response, $A$ is the concentration of drug used and $n$ is the Hill slope of the concentration response curve. The best fit values for $\mathrm{EC}_{50}, E_{\max }$ and Hill slope for each vessel segment were used to calculate the mean values \pm S.E.M. Significance limits were calculated using a paired Student's $t$-test or one way ANOVA with Dunnett's comparison, where appropriate $(P<0.05$ was taken to indicate significance). 


\section{Results}

\subsection{Measurement of lipoprotein oxidation}

Organ bath incubation for a period of $45 \mathrm{~min}$ resulted in TBARS values for chylomicron remnants of $1.96 \pm 0.34 \mathrm{nmol} \mathrm{ml}^{-1}$ MDA respectively, which did not differ significantly (by an unpaired Student's $t$-test, $n=3$ ) from lipoprotein preparations which had been freshly prepared (TBARS value $1.63 \pm 0.60 \mathrm{nmol} \mathrm{ml}^{-1}$
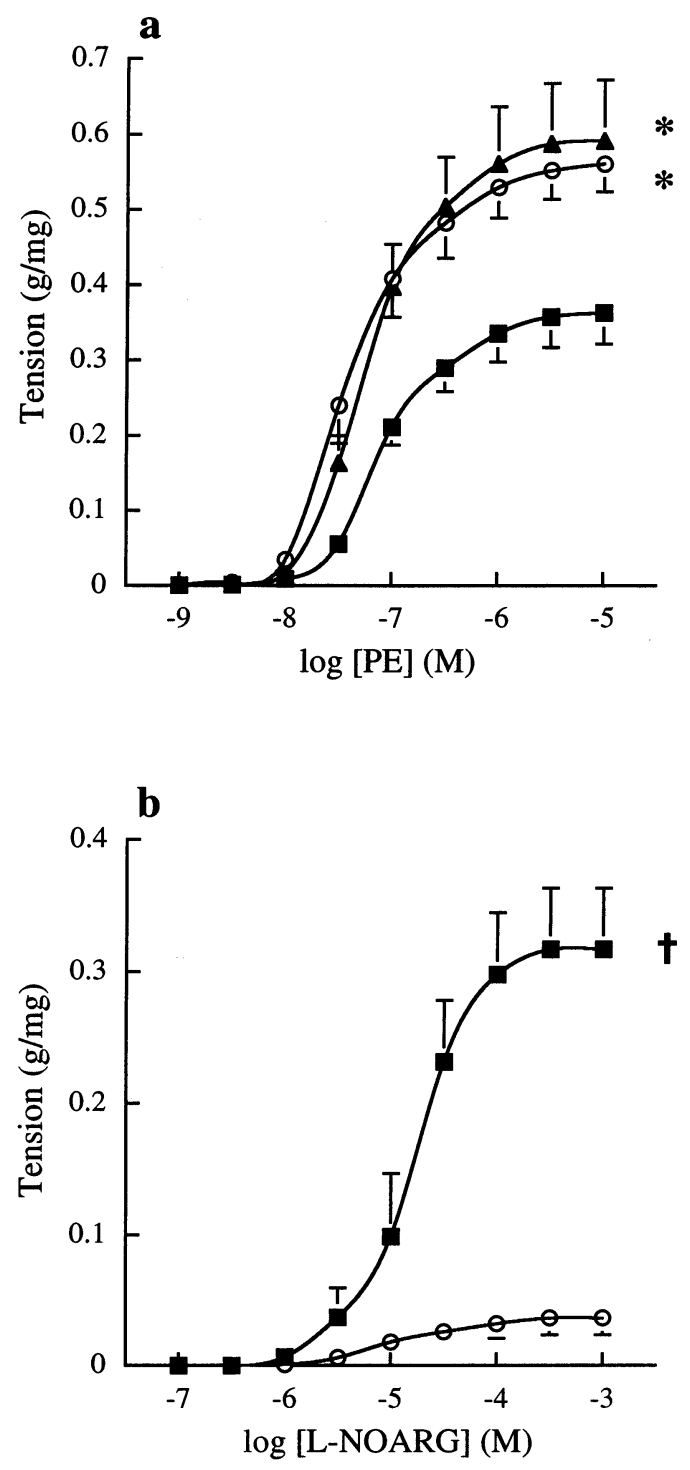

Fig. 1. Concentration contraction response curves to (a) PE and (b) L-NOARG after pre-contraction with 10 or $30 \mathrm{nM}$ PE. Endotheliumintact $(n=6, \boldsymbol{\square})$ and denuded $(n=6, \bigcirc)$ rat aortic rings and endothelium-intact rings in the presence of $0.1 \mathrm{mM}$ L-NOARG $(n=6, \boldsymbol{\Delta})$ were studied. Contraction is expressed as $\mathrm{g}$ tension produced per $\mathrm{mg}$ of tissue. Each data point represents the mean value and error bars show the S.E.M. * Significant difference in maximum response vs. endothelium-intact $(P<0.05$, one way ANOVA with Dunnett's comparison); ${ }^{\dagger}$ Significant difference in maximum response $(P<0.05$, paired Student's $t$-test $)$.
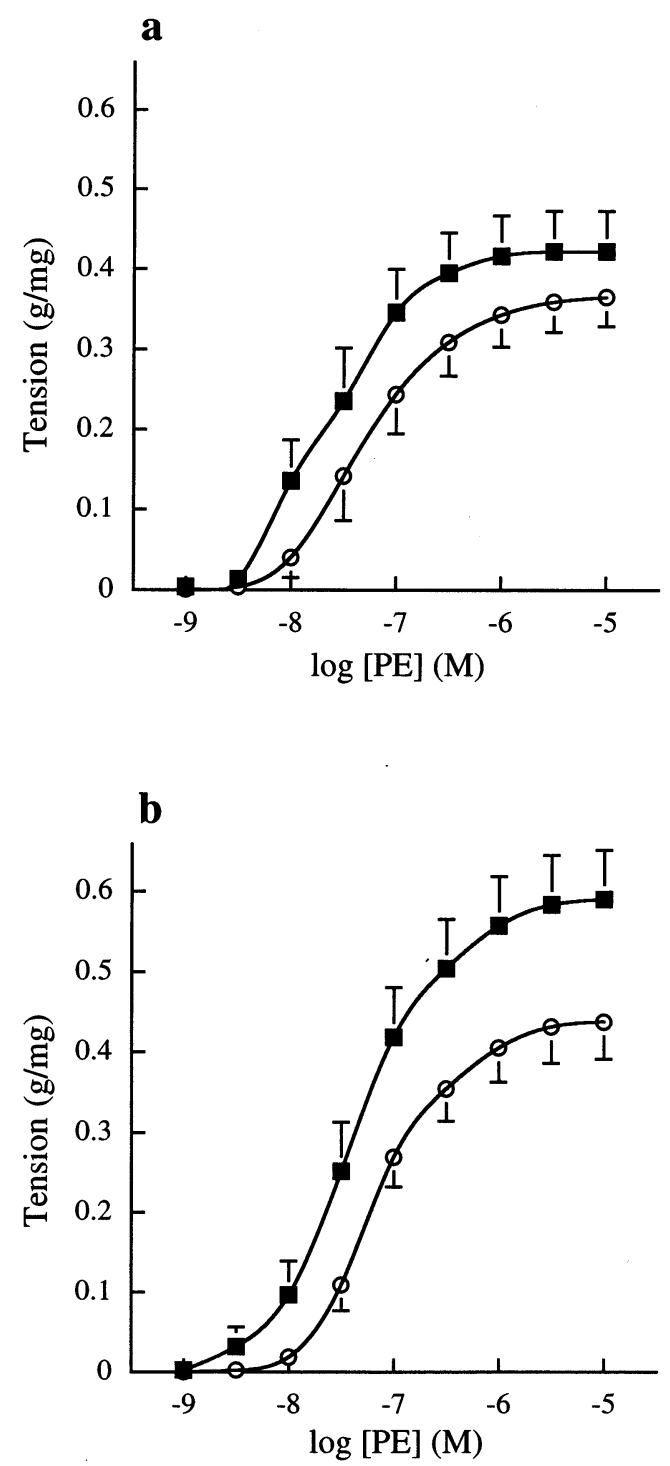

Fig. 2. Concentration contraction response curves to PE after incubation with (a) native $(n=6)$ or (b) oxidised chylomicron remnants $(n=12)$ in endothelium-intact rat aortic rings. The vessel segments were incubated with chylomicron remnants containing $100 \mu \mathrm{g} \mathrm{ml}-1$ ampicillin ( $)$ at an organ bath concentration of $16 \mu \mathrm{M}$ cholesterol or with the same volume of $100 \mu \mathrm{g} \mathrm{ml}^{-1}$ ampicillin $(\bigcirc)$ for $45 \mathrm{~min}$. Contraction is expressed as $\mathrm{g}$ tension produced per $\mathrm{mg}$ of tissue. Each data point represents the mean value and error bars show the S.E.M. The best-fit values derived from these concentration response curves are shown in Table 1.

MDA). This confirmed that the incubation period did not cause any significant oxidation of the native chylomicron remnants. Incubation with copper sulphate for a period of $18 \mathrm{~h}$ resulted in TBARS values for the oxidised chylomicron remnants of $16.03 \pm 2.80 \mathrm{nmol}$ $\mathrm{MDA} / \mathrm{ml}$, which were significantly different $(P<0.05$, unpaired Student's $t$-test, $n=3$ ) from the freshly prepared native chylomicron remnants (value given above). 


\subsection{PE-induced contraction after endothelial denudation or incubation with $L-N O A R G$}

The effects of endothelial removal and pre-treatment with L-NOARG on contractions to PE in freshly isolated rat aortic rings are shown in Fig. 1 a and b. Both endothelial denudation and incubation with L-NOARG significantly increased the maximum response to PE. In addition, it was demonstrated that L-NOARG potentiated PE-induced contractions of endothelium-intact vessel rings in a concentration-dependent manner, the maximum contraction occurring at concentrations of $0.1 \mathrm{mM}$ and above.

\subsection{PE-induced contraction after incubation with chylomicron remnants}

The effects of chylomicron remnants on contractions to PE in freshly isolated endothelium-intact rat aortic rings are shown in Fig. $2 \mathrm{a}$ and $\mathrm{b}$. The mean best fit concentration response curve parameters derived from these curves are presented in Table 1. Both native and oxidised chylomicron remnants significantly increased the vessel sensitivity to PE. In addition, oxidised chylomicron remnants significantly increased the maximum response. Native remnant particles also tended to increase the maximum response, although this did not reach statistical significance.

\subsection{PE-induced contraction after incubation with oxidised chylomicron remnants in endothelium-denuded rat aortic rings and in the presence of $L-N O A R G$}

The effects of oxidised chylomicron remnants on contractions to PE in endothelium-denuded vessel segments, and in endothelium-intact aortic rings in the presence of L-NOARG are shown in Fig. 3a and b. The mean best fit concentration response curve parameters derived from these curves are presented in Table 2. The increases in vessel sensitivity and the maximum response to PE observed in the presence of oxidised chylomicron remnants were no longer apparent after removal of the endothelium. The maximum tension developed in response to PE, however, was still significantly enhanced by oxidised chylomicron remnants when the experiments were repeated in the presence of L-NOARG.

\subsection{PE-induced contraction after incubation with oxidised chylomicron remnants and L-NOARG in the presence of $B Q-123, I D M$ or $S O D$}

In order to investigate the possibility that oxidised chylomicron remnant particles stimulate the production of endothelium-derived constricting factors (EDCFs), the effects of the $\mathrm{ET}_{\mathrm{A}}$ receptor antagonist, BQ-123, IDM and SOD, on contractions to PE in the presence of L-NOARG and oxidised chylomicron remnants were studied in freshly isolated endothelium-intact rat aortic rings. Cumulative concentration contraction response curves from this series of experiments are shown in Fig. $4 \mathrm{a}-\mathrm{d}$. The mean best-fit concentration response curve parameters derived from these curves are presented in Table 3. Neither BQ-123 or SOD alone, nor BQ-123, IDM and SOD together had any significant effect on the concentration response curves obtained to PE in the presence of oxidised chylomicron remnants and LNOARG. However, IDM alone caused a significant increase in the vessel sensitivity to PE.

\section{Discussion}

In the present study, both native and oxidised chylomicron remnants were found to potentiate PE-induced contractions of rat aorta. All previous studies on the effects of atherosclerosis and hypercholesterolaemia on endothelium-dependent contraction have focused on LDL [5] and none have investigated the actions of dietary lipoproteins. Most studies on LDL have investigated the role of the oxidised form, and those that have focused on the native particles have failed to find any significant effect $[2,3]$. Oxidised LDL has been found to potentiate endothelium-dependent responses to a number of contractile agents due to inhibition of endothelial NO production [2-4]. In the present study, we have

Table 1

Best fit values for concentration contraction response curves to PE in the presence and absence of chylomicron remnants ${ }^{\mathrm{a}}$

\begin{tabular}{lllll}
\hline Experiment & Condition & $\mathrm{EC}_{50}\left(\times 10^{-8} \mathrm{M}\right)$ & Maximum tension $(\mathrm{g} / \mathrm{mg})$ & Hill slope \\
\hline 1 & Native remnants & $3.28 \pm 0.94^{*}$ & $0.42 \pm 0.05$ & $1.53 \pm 0.19$ \\
1 & Control & $7.37 \pm 2.04$ & $0.36 \pm 0.04$ & $1.36 \pm 0.11$ \\
2 & Oxidised remnants & $6.22 \pm 1.19^{*}$ & $0.59 \pm 0.07^{*}$ & $1.25 \pm 0.06$ \\
2 & Control & $8.44 \pm 0.85$ & $0.44 \pm 0.05$ & $1.36 \pm 0.09$ \\
\hline
\end{tabular}

\footnotetext{
${ }^{\text {a }}$ Endothelium-intact rat aortic rings were incubated with native (Experiment $1, n=6$ ) or oxidised (Experiment 2, $n=12$ ) chylomicron remnants containing $100 \mu \mathrm{g} \mathrm{ml}^{-1}$ ampicillin at an organ bath concentration of $16 \mu \mathrm{M}$ cholesterol or with the same volume of $100 \mu \mathrm{g} \mathrm{ml}{ }^{-1}$ ampicillin $(n=6$ or 12) for $45 \mathrm{~min}$ before concentration contraction response curves were constructed to PE.

* Significance limits, $P<0.05$ vs. corresponding control value, each value represents the mean \pm S.E.M.
} 

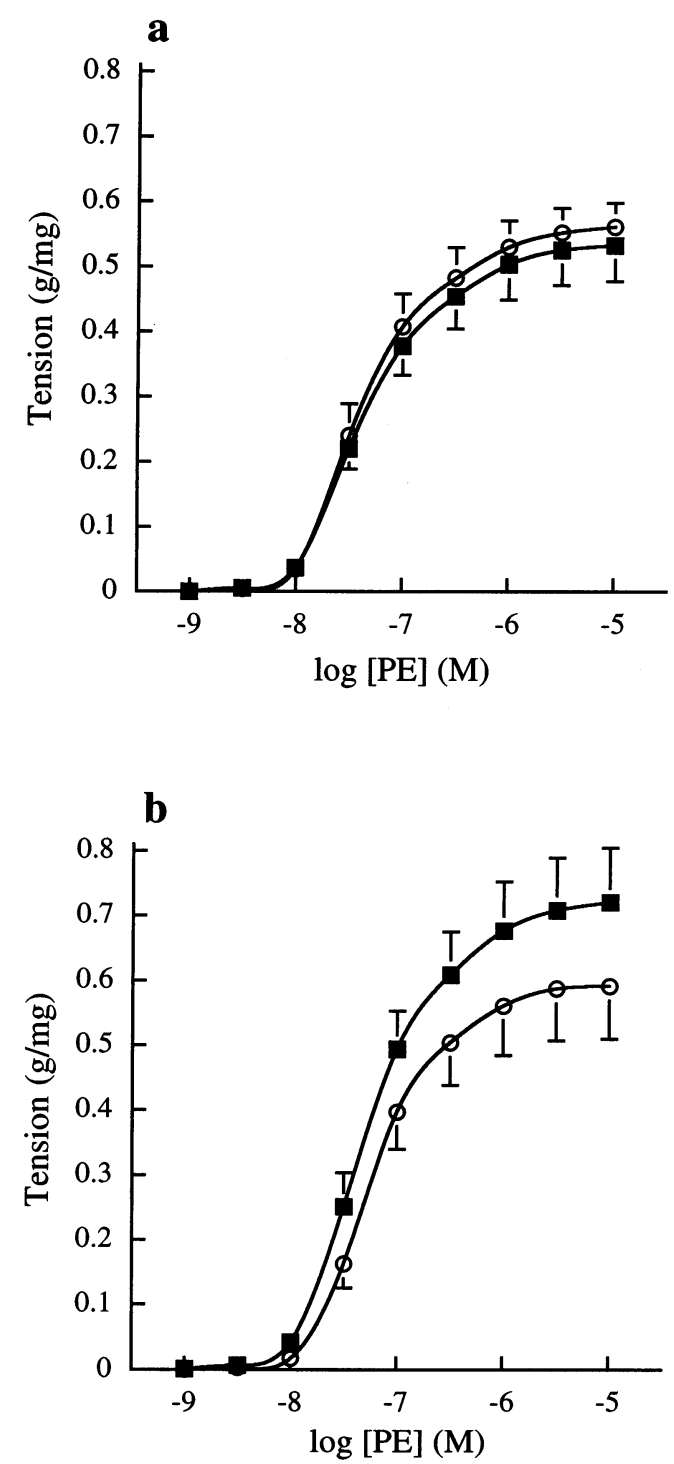

Fig. 3. Cumulative concentration contraction response curves to PE in (a) endothelium-denuded and (b) endothelium-intact rat aortic rings in the presence of $0.1 \mathrm{mM}$ L-NOARG. The vessel segments were incubated with oxidised chylomicron remnants containing $100 \mu \mathrm{g}$ $\mathrm{ml}^{-1}$ ampicillin $(n=6, \boldsymbol{\square})$ at an organ bath concentration of $16 \mu \mathrm{M}$ cholesterol or with the same volume of $100 \mu \mathrm{g} \mathrm{ml}^{-1}$ ampicillin $(n=6$, $\bigcirc$ ) for $45 \mathrm{~min}$. Contraction is expressed as g tension produced per $\mathrm{mg}$ of tissue. Each data point represents the mean value and error bars show the S.E.M. The best fit values derived from these concentration response curves are shown in Table 2.

evaluated contractions to PE as this agonist appears to be the most appropriate constrictor with which to investigate the effects of basal NO production on vascular contraction [24,25]. Many other vasoconstrictor agents also activate endothelial receptors to stimulate NO release $[9,10]$. Indeed, in the present study it was confirmed that both endothelial denudation and incubation with L-NOARG significantly increased the maximum response to PE in untreated rat aortic rings (Fig. 1a). Additional experiments demonstrated that a concentration of $0.1 \mathrm{mM}$ L-NOARG maximally potenti- ated contractions to $\mathrm{PE}$ in an endothelium-dependent manner (Fig. 1b), confirming the results of earlier studies which have shown that this concentration of $\mathrm{L}$ NOARG completely inhibits the basal production of NO [24,25].

In the present study, oxidised chylomicron remnant particles significantly increased vessel sensitivity to $\mathrm{PE}$ to a similar extent as the native particles (Fig. 2a and $\mathrm{b})$, the change in $\mathrm{EC}_{50}$ values being significant in both cases. In addition, whereas native remnants tended to increase the maximum response to PE (by $17 \%$ ), oxidised remnants increased this concentration response curve parameter to a greater extent (by $34 \%$ ), reaching statistical significance, suggesting that the effect of oxidised chylomicron remnants on PE-induced contractions was more marked than that of the native particles. These data support the suggestion that oxidative modification is involved in the atherogenic process [5]. It was therefore decided to use the oxidised chylomicron remnant particles in subsequent studies designed to determine the mechanism of potentiation of PE-induced vascular contraction. The potentiation of contractions to PE observed in the presence of oxidised chylomicron remnants was removed by endothelial denudation (Fig. 3a), but was still evident in the presence of the NO synthase inhibitor, L-NOARG (Fig. 3b), suggesting that the mechanism by which oxidised chylomicron remnants potentiate PE-induced contractions in rat aorta was endothelium-dependent, but was not due to inhibition of the basal release of NO. One possible interpretation of these findings is that oxidised remnant particles mediated their effect by either inhibition of another endothelium-derived vasodilator substance, such as prostacyclin or endothelium-derived hyperpolarising factor (EDHF), or by stimulation of the release of one or more EDCFs by oxidised chylomicron remnants. However, in preliminary studies, we found that inhibition of prostacyclin production by IDM had little effect on contractions to $\mathrm{PE}$ in rat aortic rings with intact endothelium (data not shown) and other groups have previously found that production of EDHF by large vessels of the rat is relatively low $[28,29]$. It would seem unlikely, therefore, that oxidised chylomicron remnants exert their effect via inhibition of prostacyclin or EDHF.

It is well established that constrictor substances are produced by the endothelial cells [30]. It is possible therefore that oxidised chylomicron remnants may potentiate the PE-induced contractions by stimulating the release of one or more of these EDCFs. Indeed, such a factor, endothelin, has been shown to be produced in response to oxidised LDL in porcine vessels and was found in increased concentrations in the plasma of patients with coronary artery disease and hypercholesterolaemia and also in atherosclerotic human arteries [31-34]. In addition, superoxide and a cyclo-oxygenase- 
Table 2

Best fit values for concentration contraction response curves to PE in the presence and absence of oxidised chylomicron remnants in endothelium-denuded vessel segments and endothelium-intact aortic rings after incubation with L-NOARG ${ }^{\mathrm{a}}$

\begin{tabular}{llll}
\hline Condition & $\mathrm{EC}_{50}\left(\times 10^{-8} \mathrm{M}\right)$ & Maximum tension $(\mathrm{g} / \mathrm{mg})$ & $\mathrm{Hill}$ slope \\
\hline Endothelium-denuded + oxidised remnants & $5.20 \pm 0.96$ & $0.53 \pm 0.05$ & $1.28 \pm 0.10$ \\
Endothelium-denuded, control & $5.51 \pm 1.34$ & $0.56 \pm 0.04$ & $1.36 \pm 0.08$ \\
Endothelium-intact+L-NOARG + oxidised remnants & $5.86 \pm 1.38$ & $0.72 \pm 0.08^{*}$ & $1.37 \pm 0.08^{*}$ \\
Endothelium-intact + L-NOARG, control & $6.44 \pm 1.13$ & $0.59 \pm 0.08$ & $1.48 \pm 0.07$ \\
\hline
\end{tabular}

a Endothelium-denuded and endothelium-intact rat aortic rings in the presence of $0.1 \mathrm{mM}$ L-NOARG were studied. Vessel segments were incubated with oxidised chylomicron remnants containing $100 \mu \mathrm{g} \mathrm{ml}^{-1}$ ampicillin $(n=6)$ at an organ bath concentration of $16 \mu \mathrm{M}$ cholesterol or with the same volume of $100 \mu \mathrm{g} \mathrm{ml}^{-1}$ ampicillin $(n=6)$ for $45 \mathrm{~min}$ before concentration contraction response curves were constructed to PE.

* Significance limits, $P<0.05$ vs. corresponding control value, each value represents the mean \pm S.E.M.
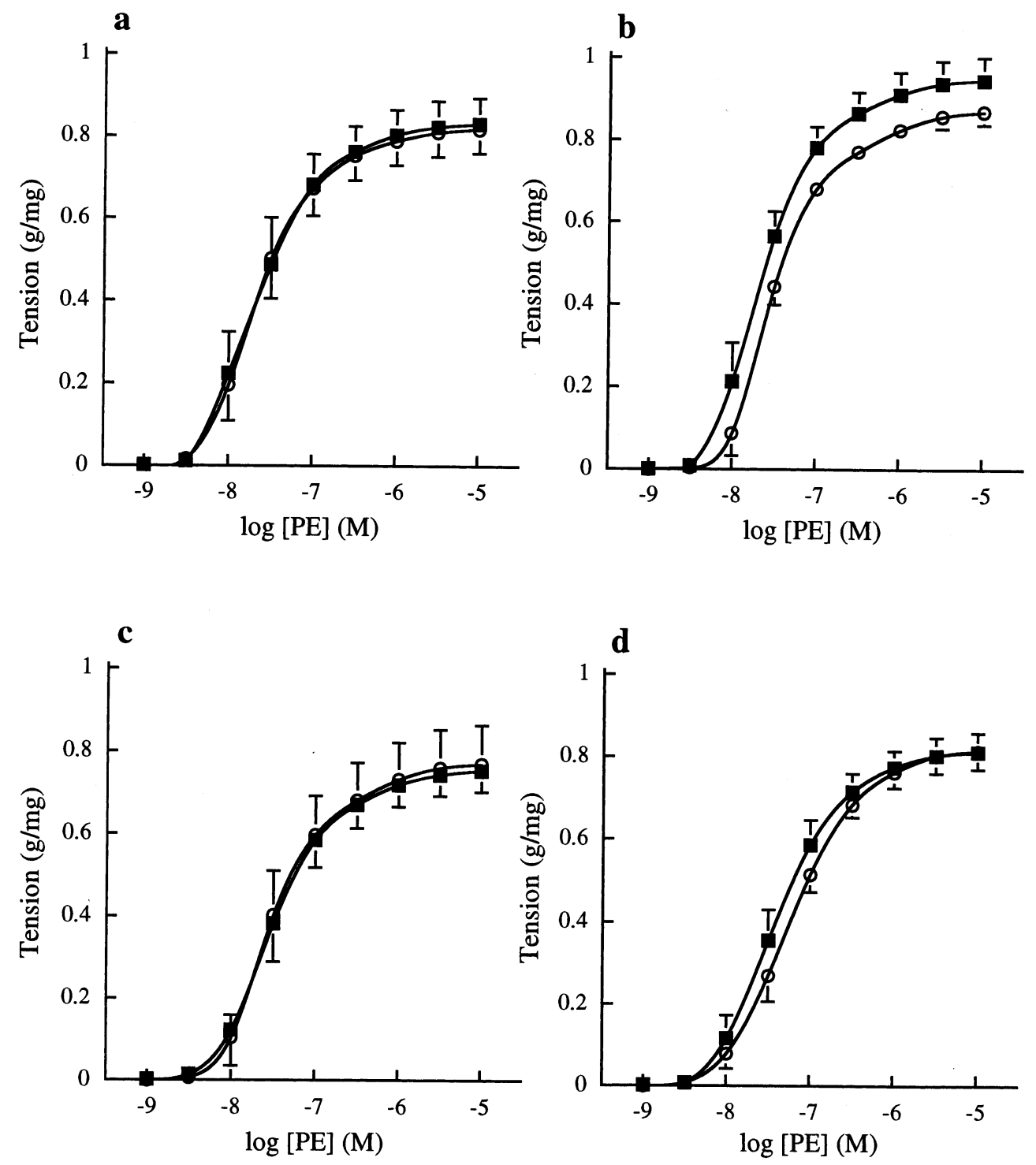

Fig. 4. Cumulative concentration contraction response curves to PE in the presence and absence of (a) BQ-123; (b) IDM; (c) SOD and (d) BQ-123, IDM and SOD together. The vessel segments were incubated with oxidised chylomicron remnants containing $100 \mu \mathrm{g} \mathrm{ml}{ }^{-1}$ ampicillin at an organ bath concentration of $16 \mu \mathrm{M}$ cholesterol for $45 \mathrm{~min}$, in the presence of $0.1 \mathrm{mM}$ L-NOARG and either $10 \mu \mathrm{M}$ BQ-123, $10 \mu \mathrm{M}$ IDM, 150 units $\mathrm{ml}^{-1} \operatorname{SOD}(n=5, \mathbf{\square})$ or all three antagonists together $(n=6, \mathbf{\square})$. Controls in which the same volume of vehicle was added to the organ bath were carried out in parallel $(n=5$ or $6, \bigcirc)$. Contraction is expressed as g tension produced per mg of tissue. Each data point represents the mean value and error bars show the S.E.M. The best-fit values derived from these concentration response curves are shown in Table 3. 
Table 3

Best fit values for concentration contraction response curves to PE in the presence of oxidised chylomicron remnants and L-NOARG with or without BQ-123, IDM and SOD

\begin{tabular}{lllll}
\hline Experiment & Condition & $\mathrm{EC}_{50}\left(\times 10^{-8} \mathrm{M}\right)$ & Maximum tension $(\mathrm{g} / \mathrm{mg})$ & Hill slope \\
\hline 1 & + BQ-123 & $3.12 \pm 1.01$ & $0.82 \pm 0.06$ & $1.56 \pm 0.13$ \\
1 & Control & $2.78 \pm 0.74$ & $0.81 \pm 0.06$ & $1.53 \pm 0.11$ \\
2 & $+\mathrm{IDM}$ & $2.63 \pm 0.67^{*}$ & $0.93 \pm 0.06$ & $1.51 \pm 0.07$ \\
2 & Control & $3.51 \pm 0.65$ & $0.86 \pm 0.03$ & $1.51 \pm 0.09$ \\
3 & + SOD & $3.94 \pm 0.99$ & $0.74 \pm 0.05$ & $1.44 \pm 0.08$ \\
3 & Control & $3.90 \pm 1.04$ & $0.76 \pm 0.09$ & $1.45 \pm 0.08$ \\
4 & + BQ-123+IDM+SOD & $4.90 \pm 1.48$ & $0.80 \pm 0.05$ & $1.39 \pm 0.09$ \\
4 & Control & $6.49 \pm 1.57$ & $0.81 \pm 0.04$ & $1.26 \pm 0.09$ \\
\hline
\end{tabular}

\footnotetext{
${ }^{a}$ Endothelium-intact rat aortic rings were incubated with oxidised chylomicron remnants containing $100 \mu \mathrm{g} \mathrm{ml}{ }^{-1}$ ampicillin at an organ bath concentration of $16 \mu \mathrm{M}$ cholesterol for $45 \mathrm{~min}$, in the presence of $0.1 \mathrm{mM} \mathrm{L}-\mathrm{NOARG}$ and either $10 \mu \mathrm{M}$ BQ-123 (Experiment $1, n=5$ ), $10 \mu \mathrm{M}$ IDM (Experiment 2,n=5), 150 units $\mathrm{ml}^{-1} \mathrm{SOD}$ (Experiment 3,n=5), all three antagonists together (Experiment 4, $n=6$ ) or the same volume of vehicle $(n=5$ or 6$)$ before concentration contraction response curves were constructed to PE.

* Significance limits, $P<0.05$ vs. corresponding control value, each value represents the mean \pm S.E.M.
}

derived product, thromboxane $\mathrm{A}_{2}$, both of which have also been proposed as EDCFs, have been found in increased concentrations in hypercholesterolaemic rabbit vessels $[35,36]$. Furthermore, macrophage superoxide generation has been shown to be stimulated by LDL and the expression of endothelial cyclo-oxygenase mRNA increased by oxidised LDL $[37,38]$.

Antagonists of these three candidate EDCFs were used in an attempt to elucidate the mechanism of action of oxidised chylomicron remnants on PE-induced contraction. Concentration contraction response curves were constructed to PE in the presence of both oxidised chylomicron remnants and L-NOARG either in the presence or absence of BQ-123 $(10 \mu \mathrm{M})$, IDM $(10 \mu \mathrm{M})$ or SOD (150 units $\left.\mathrm{ml}^{-1}\right)$. It has been previously established that these drugs, at the chosen concentrations, inhibit the action of endothelin, prevent the production of cyclo-oxygenase-derived products and destroy superoxide, respectively, in the rat aorta $[25,39,40]$, findings that were confirmed by studies in our own laboratory (data not shown). It was also established that in the absence of chylomicron remnants, none of these inhibitors had any significant effect on concentration contraction response curves to PE. Thus, if oxidised chylomicron remnants did indeed stimulate the production of endothelin, cyclo-oxygenase-derived products or superoxide, addition of one or all of these drugs to the bathing solution should have reduced the maximum response obtained to PE. However, BQ-123, IDM, or SOD alone, or all three drugs added together, did not cause any significant effect on the maximum contraction to PE in the presence of L-NOARG and oxidised remnant particles (Fig. $4 \mathrm{a}-\mathrm{d}$ ). These data suggest that oxidised chylomicron remnants do not enhance PE-induced contractions by stimulating the release of endothelin, cyclo-oxygenase-derived products or superoxide from the endothelium. However, in the pres- ence of IDM, vessel sensitivity to PE was slightly, but significantly, increased. This effect is the opposite of that which would have been expected if oxidised chylomicron remnants were stimulating the release of $c y$ clo-oxygenase-derived products from the endothelium. In the absence of chylomicron remnants, prostacyclin production did not appear to limit the contractile response of the rat aorta to PE (data not shown). However, it is possible that the chylomicron remnants stimulated the release of a constrictor agent and prostacyclin simultaneously and the observed potentiation of contraction to PE was limited by prostacyclin.

In conclusion, the results from the present study have shown that both native and oxidised chylomicron remnants potentiate PE-induced contraction of the rat aorta. Oxidised chylomicron remnants appeared to potentiate contractions to PE to a greater extent than the native particles. This effect was endothelium-dependent, but was not due to inhibition of the basal production of $\mathrm{NO}$, nor to the stimulation of endothelin, superoxide or a cyclo-oxygenase-derived product. This is the first study to demonstrate that chylomicron remnant particles can potentiate the action of a vasoconstrictor agent in an endothelium-dependent manner, further to their inhibitory effects on vascular relaxation [21]. In addition, these findings also support the suggestion that oxidative modification of lipoproteins is involved in the atherogenic process. Further experiments are required, however, to elucidate the exact mechanism by which lipoproteins of dietary origin cause endothelium-dependent potentiation of PE-induced contraction.

\section{Acknowledgements}

We thank the Medical Research Council for their financial support. 


\section{References}

[1] Woodman OL. Modulation of vasoconstriction by endotheliumderived nitric oxide: the influence of vascular disease. Clin Exp Pharmacol Physiol 1995;22:585-93.

[2] Galle J, Bassenge E, Busse R. Oxidized low-density lipoproteins potentiate vasoconstrictions to various agonists by direct interaction with vascular smooth muscle. Circ Res 1990;66:1287-93.

[3] Murohara T, Kugiyama K, Ohgushi M, Sugiyama S, Ohta Y, Yasue H. LPC in oxidised LDL elicits vasocontraction and inhibits endothelium-dependent relaxation. Am J Physiol 1994;267:H2441-9.

[4] McPherson KL, Hamilton CA, Dominiczak AF, McIntyre M, Reid JL. Effects of oxidised LDL on basal and stimulated nitric oxide release in rat aorta. Br J Pharmacol 1995;116:317P.

[5] Cox DA, Cohen ML. Effects of oxidized low-density lipoprotein on vascular contraction and relaxation: clinical and pharmacological implications in atherosclerosis. Pharmacol Rev 1996;48:3-19.

[6] Singer AH, Tsao PS, Wang BY, Bloch DA, Cooke JP. Discordant effects of dietary L-arginine on vascular structure and reactivity in hypercholesterolaemic rabbits. J Cardiovasc Pharmacol 1995;25:710-6.

[7] Verbeuren TJ, Bonhomme E, Laubie M, Simonet S. Evidence for induction of nonendothelial NO synthase in aortas of cholesterol-fed rabbits. J Cardiovasc Pharmacol 1993;21:841-5.

[8] Cox DA, Cohen ML. Selective enhancement of 5-hydroxytryptamine-induced contraction of porcine coronary artery by oxidised low-density lipoprotein. J Pharmacol Exp Ther 1996;276:1095-103.

[9] Vanhoutte PM, Miller VM. Alpha 2-adrenoceptors and endothelium-derived relaxing factor. Am J Med 1989;87:1S-5S.

[10] Vanhoutte PM. Vascular effects of serotonin and ischaemia. J Cardiovasc Pharmacol 1990;16(Suppl 3):S15-9.

[11] Mamo JCL, Wheeler JR. Chylomicrons or their remnants penetrate rabbit thoracic aorta as efficiently as do smaller macromolecules, including low-density lipoprotein, high-density lipoprotein, and albumin. Cor Art Dis 1994;5:695-705.

[12] Proctor SD, Mamo JCL. Arterial fatty lesions have increased uptake of chylomicron remnants but not low-density lipoproteins. Cor Art Dis 1996;7:239-45.

[13] Cardona-Sanclemente LE, Medina R, Born GVR. Effect of increasing doses of angiotensin II into normal and hypertensive Wistar rats on low density lipoprotein and fibrogen uptake by aortic walls. Proc Natl Acad Sci USA 1994;91:3285-8.

[14] Proctor SD, Pabla CK, Mamo JCL. Arterial uptake of chylomicrons and low density lipoproteins in insulin deficient rats and rabbits. Atherosclerosis 1997;134:314.

[15] Yla-Herttuala S, Jaakkola O, Ehnholm C, Tikkanen MJ, Solakivi T, Sarkioja T, Nikkari T. Characterization of two lipoproteins containing apolipoproteins $\mathrm{B}$ and $\mathrm{E}$ from lesion-free human aortic intima. J Lipid Res 1988;29:563-72.

[16] Mamo JCL, Elsegood CL, Gennat HC, Yu K. Degradation of chylomicron remnants by macrophages occurs via phagocytosis. Biochemistry 1996;35:10210-4.

[17] Yu KC-W, Smith D, Yamamoto A, Kawaguchi A, HaradaShiba M, Yakamura T, Mamo JCL. Phagocytic degradation of chylomicron remnants by fibroblasts from subjects with homozygous familial hypercholesterolaemia. Clin Sci 1997;92:197203.

[18] Yu KC-W, Mamo JCL. Killing of arterial smooth muscle cells by chylomicron remnants. Biochem Biophys Res Commun 1996;220:68-71.

[19] Mahley RW, Weisgraber KH, Innerarity TL, Rall SC Jr. Genetic defects in lipoprotein metabolism. J Am Med Assoc 1991;265:78-83.
[20] Weintraub M, Burstein A, Rassin T, Liron M, Ringel Y, Cabili S, Blum M, Peer G, Iaina A. Severe defect in clearing postprandial chylomicron remnants in dialysis patients. Kidney Int 1992;42:1247-52.

[21] Grieve DJ, Avella MA, Botham KM, Elliott J. Effects of chylomicrons and chylomicron remnants on endothelium-dependent relaxation of rat aorta. Eur J Pharmacol 1998;348:181-90.

[22] Grieve DJ, Avella MA, Elliott J, Botham KM. The influence of chylomicron remnants on endothelial cell function in the isolated perfused rat aorta. Atherosclerosis 1998;139:273-81.

[23] Doi H, Kugiyama K, Ohgushi M, Sugiyama S, Matsumura T, Ohta Y, Nakano T, Nakajima K, Yasue H. Remnants of chylomicron and very low-density lipoprotein impair endothelium-dependent vasorelaxation. Atherosclerosis 1998;137:341-9.

[24] Frew JD, Paisley K, Martin W. Selective inhibition of basal but not agonist-stimulated activity of nitric oxide in rat aorta by $N^{\mathrm{G}}$-monomethyl-L-arginine. Br J Pharmacol 1993;110:1003-8.

[25] Mian KB, Martin W. Differential sensitivity of basal and acetylcholine-stimulated activity of nitric oxide to destruction by superoxide anion in rat aorta. Br J Pharmacol 1995;115:993-1000.

[26] Deckert V, Persegol L, Viens L, Lizard G, Athias A, Lallemant C, Gambert P, Lagrost L. Inhibitors of arterial relaxation among components of human oxidized low-density lipoproteins. Circulation 1997;95:723-31.

[27] Steinbrecher UP, Parthasarathy S, Leake DS, Witztum JL, Steinberg D. Modification of low density lipoprotein by endothelial cells involves lipid peroxidation and degradation of low density lipoprotein phospholipids. Proc Natl Acad Sci USA 1984;81:3883-7.

[28] Chen G, Suzuki H, Weston AH. Acetylcholine releases endothelium-derived hyperpolarizing factor and EDRF from rat blood vessels. Br J Pharmacol 1988;95:1165-74.

[29] Shimokawa H, Yasutake H, Fujii K, et al. The importance of the hyperpolarizing mechanism increases as the vessel size decreases in endothelium-dependent relaxations in rat mesenteric circulation. J Cardiovasc Pharmacol 1996;28:703-11.

[30] Noll G, Luscher TF. Influence of lipoproteins on endothelial function. Thromb Res 1994;74(Suppl 1):S45-54.

[31] Boulanger CM, Tanner FC, Bea M-L, Hahn AWA, Werner A, Luscher TF. Oxidized low-density lipoproteins induce mRNA expression and release of endothelin from human and porcine endothelium. Circ Res 1992;70:1191-7.

[32] Arendt RM, Wilbert-Lampen U, Heucke L, Schmoeckel M, Suhler K, Richter WO. Increased endothelin plasma concentrations in patients with coronary artery disease or hyperlipoproteinemia without coronary events. Res Exp Med 1993;193:225-30.

[33] Mangiafico RA, Malatino LS, Santonocito M, Spada RS, Polizzi G, Tamburino G. Raised plasma endothelin-1 concentrations in patients with primary hypercholesterolemia without evidence of atherosclerosis. Int Angiol 1996;15:240-4.

[34] Jones GT, van Rij AM, Solomon C, Thomson IA, Packer SGK. Endothelin-1 is increased overlying atherosclerotic plaques in human arteries. Atherosclerosis 1996;124:25-35.

[35] Ohara Y, Peterson TE, Harrison DG. Hypercholesterolemia increases endothelial superoxide anion production. J Clin Invest 1993;91:2546-51.

[36] Kawaguchi H, Ishibashi T, Imai Y. Increased thromboxane B2 biosynthesis in platelets. Lipids 1982;17:577-84.

[37] Kimura H, Minakami H, Kimura S, Sakurai T, Nakamura T, Kurashige S, Nakano M, Shoji A. Release of superoxide radicals by mouse macrophages stimulated by oxidative modification of glycated low density lipoproteins. Atherosclerosis 1995;118:1-8.

[38] Maier JA, Barenghi L, Bradamante S, Pagani F. Modulators of oxidized LDL-induced hyperadhesiveness in human endothelial cells. Biochem Biophys Res Commun 1994;204:673-7. 
[39] Warner TD, Allcock GH, Vane JR. Reversal of established responses to endothelin-1 in vivo and in vitro by the endothelin antagonists, BQ-123 and PD 145065. $\mathrm{Br}$ J Pharmacol 1994;112:207-13.
[40] Auch-Schwelk W, Katusic ZS, Vanhoutte PM. Contractions to oxygen-derived free radicals are augmented in aorta of the spontaneously hypertensive rat. Hypertension 1989;13:85964. 